\title{
BUD2, encoding an S-adenosylmethionine decarboxylase, is required for Arabidopsis growth and development
}

\author{
Chunmin $\mathrm{Ge}^{1,2, *}$, Xia Cui ${ }^{1,2, *}$, Yonghong Wang ${ }^{1}$, Yuxin $\mathrm{Hu}^{3}$, Zhiming $\mathrm{Fu}^{1}$, Dongfen Zhang ${ }^{1,2}$, Zhukuan Cheng ${ }^{1}$, \\ Jiayang $\mathrm{Li}^{1}$ \\ ${ }^{I}$ State Key Laboratory of Plant Genomics and National Center for Plant Gene Research, Institute of Genetics and Developmental \\ Biology, Chinese Academy of Sciences, Beijing 100101, China; ${ }^{2}$ Graduate School, Chinese Academy of Sciences, Beijing 100101, \\ China; ${ }^{3}$ Institute of Botany, Chinese Academy of Sciences, Beijing 100093, China
}

Polyamines are implicated in regulating various developmental processes in plants, but their exact roles and how they govern these processes still remain elusive. We report here an Arabidopsis bushy and dwarf mutant, bud2, which results from the complete deletion of one member of the small gene family that encodes S-adenosylmethionine decarboxylases (SAMDCs) necessary for the formation of the indispensable intermediate in the polyamine biosynthetic pathway. The bud2 plant has enlarged vascular systems in inflorescences, roots, and petioles, and an altered homeostasis of polyamines. The double mutant of $b u d 2$ and samdc1, a knockdown mutant of another SAMDC member, is embryo lethal, demonstrating that SAMDCs are essential for plant embryogenesis. Our results suggest that polyamines are required for the normal growth and development of higher plants.

Cell Research (2006) 16:446-456. doi:10.1038/sj.cr.7310056; published online 15 May 2006

Keywords: BUD2, polyamines, embryogenesis, plant architecture, Arabidopsis

\section{Introduction}

Polyamines, including diamine putrescine, triamine spermidine and tetraamine spermine, are aliphatic nitrogen compounds distributed widely from bacteria to higher plants $[1,2]$ and have been implicated to play important roles in growth and development [3]. At the cellular level, polyamines are organic cations, interacting with the macromolecules that possess anionic groups such as DNA, RNA, lipids and proteins, thereby influencing DNA conformation, gene expression and protein synthesis, and modulating enzyme activity. In higher plants, polyamines are able to affect membrane fluidity by binding to phospholipids in membrane [4] and mediate biotic and abiotic stress responses, such as pathogen infection, osmotic stress,

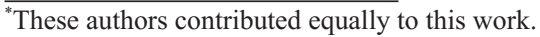

Correspondence: Jiayang $\mathrm{Li}$

Tel: 86-10-64852855; Fax: 86-10-64873428;

E-mail: jyli@genetics.ac.cn

Received 10 Jan 2006; revised 20 Feb 2006; accepted 26 Feb 2006; published online 15 May 2006
}

potassium deficiency and wounding [5-9]. Previous observations revealed that polyamines may be involved in a variety of plant developmental processes, such as cell division, root initiation, somatic embryogenesis, xylogenesis, flower development, fruit ripening and senescence [3]. Recent studies have indicated that polyamines also affect the formation of plant architecture, such as internode elongation [10,11], root branching [12] and shoot apical dominance [13].

The plant polyamine biosynthetic pathway is relatively simple [14]. Putrescine is derived either from ornithine catalyzed by ornithine decarboxylase (ODC) or from arginine through several steps catalyzed by arginine decarboxylase (ADC), agmatine iminohydrolase and N-carbamoylputrescine amidohydrolase. Spermidine and spermine are synthesized from putrescine through spermidine and spermine synthases (SPDS and SPMS) from the donor of decarboxylated S-adenosylmethionine (dcSAM), which is produced from S-adenosylmethionine (SAM) by the action of S-adenosylmethionine decarboxylase (SAMDC).

Although application of inhibitors is very useful in studying the polyamine biosynthetic pathway and in ex- 
ploring the functions of polyamines, isolation of mutants defective in polyamine biosynthesis can provide us a more powerful tool to understand their roles in plant growth and development, as the cases in yeast $[15,16]$, Leishmania donovani [17] and mouse embryonic cells [18], in which mutations in $S A M D C$ cause an absolute requirement of spermidine and/or spermine in the media for survival. In Arabidopsis thaliana, mutants defective in ADC, SPMS and SPDS have been identified [11, 19-24]. However, no mutant defective in $S A M D C$ has been reported yet, although $S A M D C$ cDNAs were cloned and their transgenic plants have been generated [25-29]. In this paper, we report the isolation and characterization of an Arabidopsis bushy and dwarf mutant, bud2. BUD2 encodes SAMDC4, a member of the SAMDC family. Our data indicate that SAMDCs are essential for plant embryogenesis and polyamines play an important role in plant growth and development.

\section{Materials and methods}

\section{Plant growth, plasmid construction and plant transforma- tion}

Arabidopsis thaliana ecotype Columbia- 0 (Col-0) wild type and mutant plants were grown on vermiculite saturated with $0.3 \times \mathrm{B}_{5}$ medium under continuous illumination $\left(80-120 \mu \mathrm{E} \mathrm{m}^{-2} \mathrm{~s}^{-1}\right)$ at $23{ }^{\circ} \mathrm{C}$ as described by Mou [30]. For root observation, seeds were surface sterilized and vernalized at $4{ }^{\circ} \mathrm{C}$ for 4 days and seedlings were grown vertically at $23{ }^{\circ} \mathrm{C}$ for 22 days.

For the complementation test, a $3.5-\mathrm{kb}$ entire $B U D 2$ gene $(1.5-\mathrm{kb}$ promoter, 1.044-kb coding sequence and 1.0-kb 3' region) was amplified by PCR using the primers of PFB (5'ATG ATG AGGGATCC ATA A3') and PRK (5'TAG GGTACC AGT TTC AAG TTA TGC3'), and the PCR product was cloned into the binary vector pCAMBIA 1300 digested with BamHI and KpnI. For the antisense BUD2 construct, BUD2 cDNA was amplified with primers $5^{\prime} \mathrm{CTC}$ TTC TCT CTC TAC TCA CAC AC3' and 5'GCG TGA CAT TGC CAC AAG TC3', and ligated into the pGEM-T Easy vector (Promega, USA). The EcoRI-digested BUD2 cDNA was inserted into the pJL453 vector in an antisense orientation, and then cloned into pCAMBIA1300. The constructs were introduced into Agrobacterium tumefaciens strain GV3101 (pMP90RK) by electroporation and transformation was performed as described previously [31]. Transformants were selected on $0.5 \times \mathrm{MS}$ agar plates supplemented with $40 \mathrm{mg} \mathrm{L}^{-1}$ hygromycin and $50 \mathrm{mg} \mathrm{L}^{-1}$ kanamycin. $\mathrm{T}_{2}$ plants were self-pollinated, and the $\mathrm{T}_{3}$ homozygous plants with a single insertion locus were used for detailed analyses.

\section{DNA fiber FISH}

Leaf nuclei were prepared according to the method described previously [32]. A $2-\mu \mathrm{L}$ suspension of nuclei was deposited at an end of a poly-L-lysine slide (Sigma, St. Louis, USA) and air dried for 5-10 min. Eight microliter of STE ( $0.5 \%(\mathrm{w} / \mathrm{v})$ SDS, $5 \mathrm{mM}$ EDTA, $100 \mathrm{mM}$ Tris, $\mathrm{pH}$ 7.0) lysis buffer was pipetted on top of the nuclei, and slide was left at room temperature for $4 \mathrm{~min}$. A clean coverslip was slowly dragged through samples. The slide was air dried, fixed in 3:1 ethanol: glacial acetic acid for $2 \mathrm{~min}$ and baked at $60^{\circ} \mathrm{C}$ for
$30 \mathrm{~min}$. The BAC clone DNA was isolated, and labeled with either biotin-11-dUTP or digoxigenin-16-dUTP (Roche, Switzerland) by nick translation. The probe mixture $(20 \mu \mathrm{L})$ was applied to the DNA fiber preparation, covered with a coverslip. The slide was placed in an $80^{\circ} \mathrm{C}$ oven for $3 \mathrm{~min}$ and transferred to $37^{\circ} \mathrm{C}$ for overnight incubation. Post-hybridization washing and signal detection were performed accordingly. Fiber FISH signal images were captured under the Olympus BX61 fluorescence microscope conjunct with a microCCD camera. Grayscale images were captured for each color channel, and then merged using the software of Image-Pro Plus.

\section{RNA isolation, RACE-PCR and RNA gel blot}

Total RNA was isolated with TRIzol reagent (Invitrogen, USA). The full-length $B U D 2$ cDNA was amplified with a RACE Kit (Clontech, USA). The first strand cDNA was synthesized from $2.5 \mu \mathrm{g}$ total RNA by using a cDNA synthesis kit (Promega, USA). RNA gel-blot analysis was carried out as described previously [33] with specific probes for each gene (Supplement 1).

\section{Yeast complementation}

$B U D 2$ cDNA was digested with Not 1 , cloned into the yeast expression vector pREP5N [34] and introduced into yeast mutant spe 2 cells [35]. Yeast cells were cultured as described by Gupta [36]. After a single clone was cultured in YPD medium for $24 \mathrm{~h}$, the $10-\mu \mathrm{L}$ cultured cells were added to 5-mL SD medium with or without supplement of spermidine and were incubated overnight at $30^{\circ} \mathrm{C}$. Cells were then diluted 500 times and $\mathrm{A}_{600}$ was measured at intervals of $4 \mathrm{~h}$.

\section{Measurement of cellulose, lignin and polyamines}

Lignin and cellulose contents were assayed according to the methods described previously [37,38]. Analysis of polyamines was carried out according to the method described by Flores and Galston [39] with some modifications. Seedlings of $100 \mathrm{mg}$ were homogenized in $1 \mathrm{~mL}$ of $5 \%(\mathrm{w} / \mathrm{v})$ perchloric acid containing $10 \mathrm{nmol}$ of 1,7-diaminoheptane $2 \mathrm{HCl}$ as the internal standard and cooled on ice for $1 \mathrm{~h}$. The homogenate was centrifuged at $4800 \mathrm{~g}$ for $20 \mathrm{~min}$ and the soluble polyamines in the supernatant were used for benzoylation. After drying under warm air, the benzoylated polyamines were redissolved in $100 \mu \mathrm{L}$ of methanol and analyzed by HPLC (Model Agilent 1100 , Agilent, USA). A $20-\mu \mathrm{L}$ sample was applied to a reverse-phase C18 column (particle size $5 \mu \mathrm{m}, 4.6 \times 250 \mathrm{~mm}$, Agilent), eluted with acetonitrile in water (a gradient of $36 \%$ to $41 \%$ for $8 \mathrm{~min}$, followed by a 10 -min elution of $41 \%$ and a gradient of $41 \%$ to $100 \%$ for 7 $\mathrm{min}$ ) at a flow rate of $1 \mathrm{~mL} / \mathrm{min}$ at room temperature, and monitored at 254 and $360 \mathrm{~nm}$, respectively.

\section{Microscopy and histology}

Sections of inflorescences, roots, and petioles were prepared according to the method described previously [40] and stained with Safranin O and Fast Green (Fisher, USA). To observe the vascular patterns of Arabidopsis inflorescences and roots, the fresh hand-cut sections or microtome-sliced sections were observed directly under the UV light at 340-380 nm [41]. For histochemical localization of lignin, freshly hand-cut sections ( $20 \mu \mathrm{m}$ thick) of inflorescences or roots were incubated for $2 \mathrm{~min}$ in $2 \%$ phloroglucine solution (Sigma, USA), mounted in $50 \% \mathrm{HCl}$ [42] and photographed with a Micro Color CCD camera (Apogee Instruments INC, USA).

Embryos were observed according to the method described previously [43]. Seeds of 1-12 day-old were removed from the siliques 

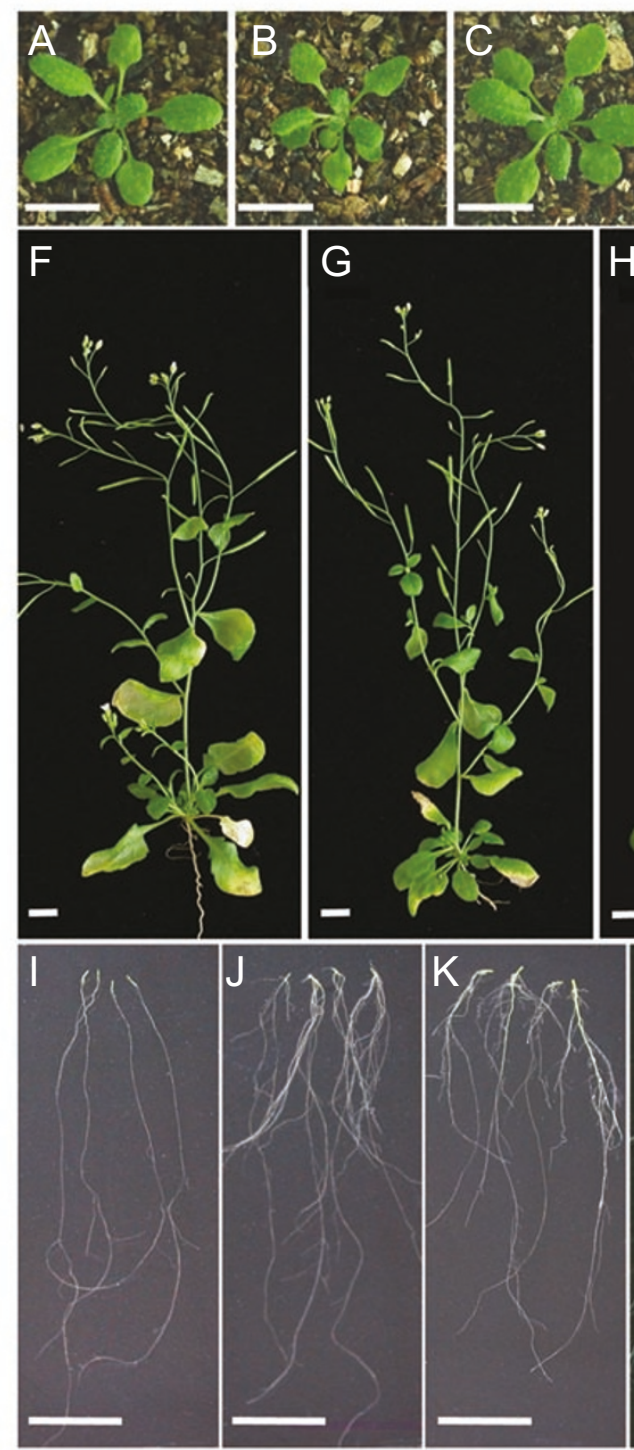
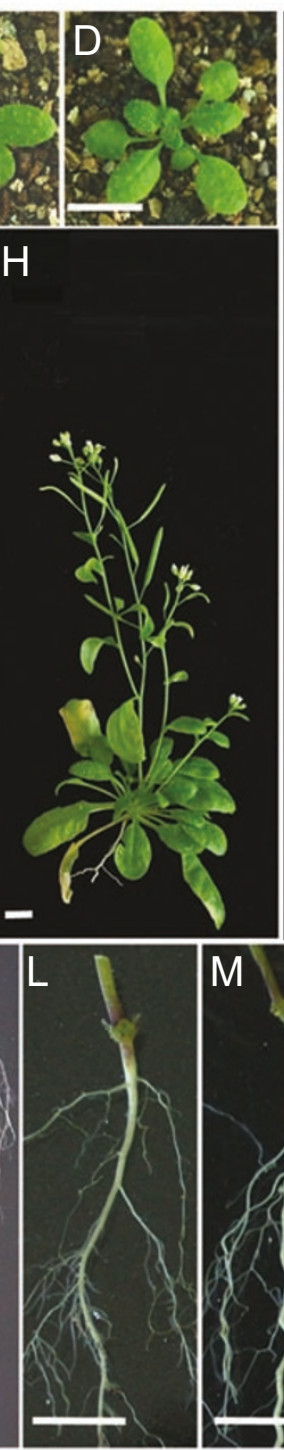

$\mathrm{H}$
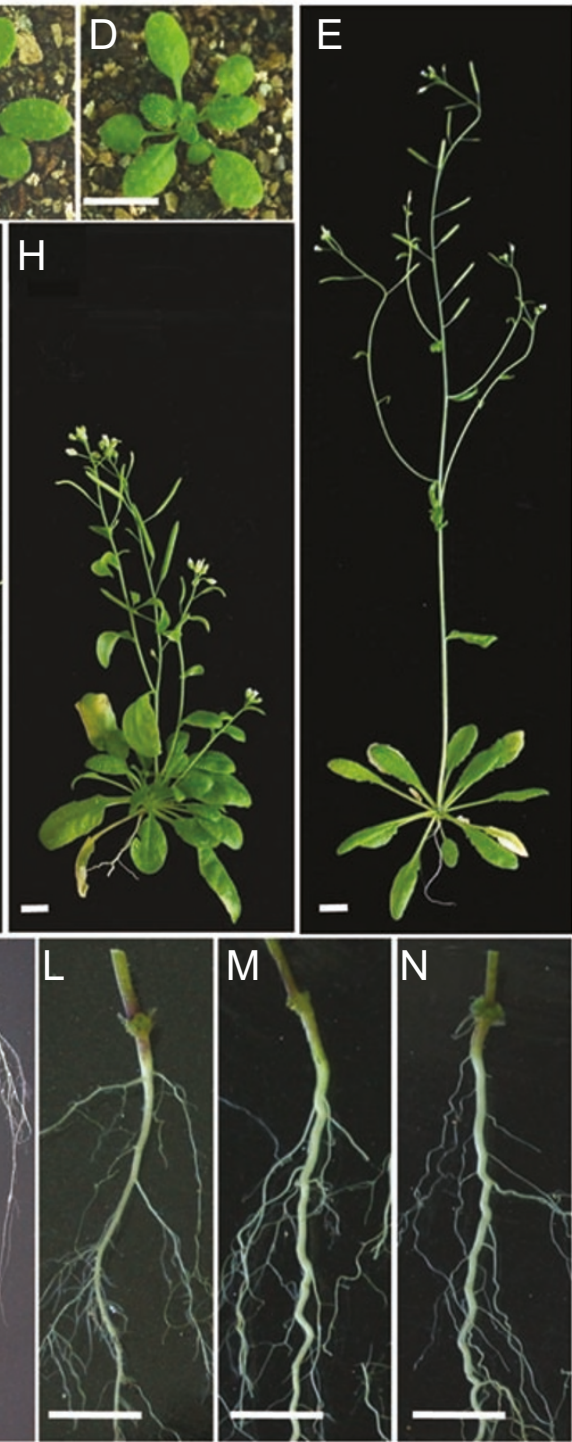

Figure 1 Morphology of bud2 and related mutants. (A) to (D) 26-day-old plants of wild type (A), bud2-1 (B), bud2-2 (Salk 007279) (C) and samdc1-1 (D). (E) to (H) 50-day-old plants of wild type (E), bud2-1 (F), bud2-2 (G) and samdc1-1 (H). (I) to (K) Roots of wild type (I), bud2-1 (J) and bud2-2 (K). Plants were grown on $0.5 \times$ MS plates vertically for 22 days. (L) to (N) The primary and lateral roots of wild type (L), bud2-1 (M) and bud2-2 (N). Plants were grown on greenhouse for 50 days. Bars=1 cm.

and observed after transparency treatment under the Olympus BX61 differential interference contrast microscope conjunct with a CCD camera.

\section{Results}

Isolation and morphological characterization of bud2 mutant

Two mutants with obviously bushy and dwarf phenotype after flowering were isolated from a mutant collection generated with a sense/antisense RNA expression system
(SARE) [44] and were designated as bud1 [45] and bud2-1 (Figure 1), respectively.

Compared with the wild type, bud2-1 plants displayed smaller and slightly curled leaves in seedlings, but severe morphological alterations were observed in plant height, apical dominance, length of internodes and petioles and the number of lateral roots (Figures 1B, 1F and 1J). Quantitative analysis revealed that the plant height and length of petioles in bud2-1 decreased by $\sim 57 \%$ and $37 \%$ compared to those of wild type, respectively. The hypocotyl length of the bud2-1 seedling grown in the dark was comparable 

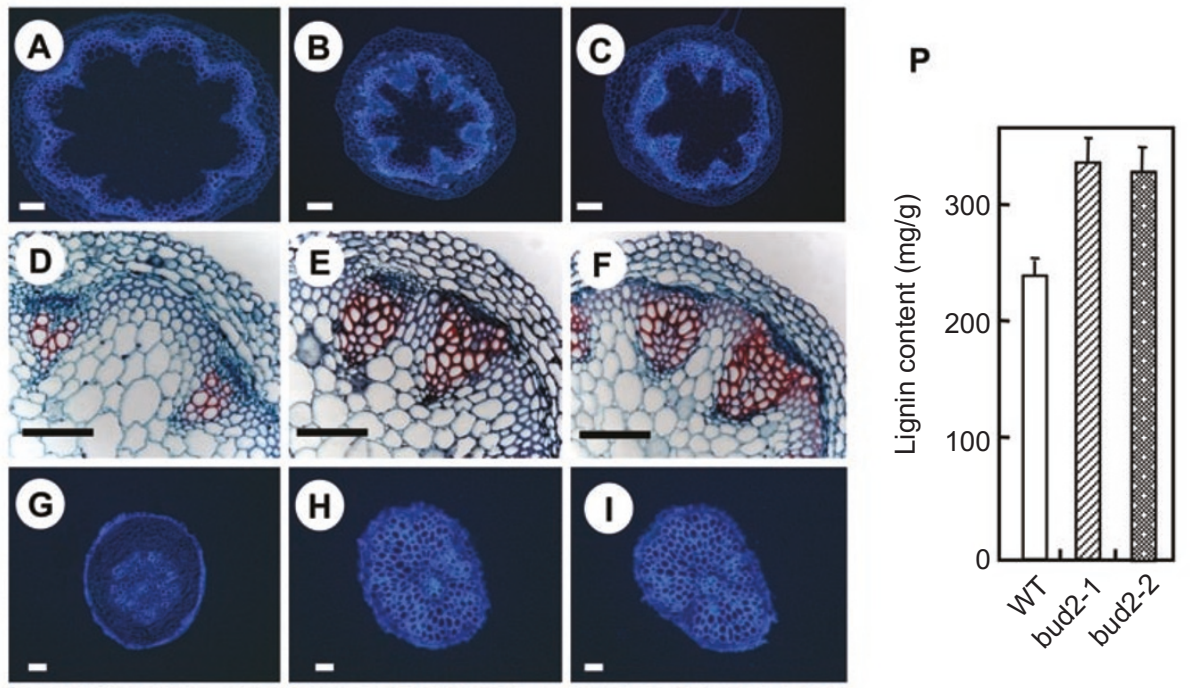

$\mathbf{Q}$
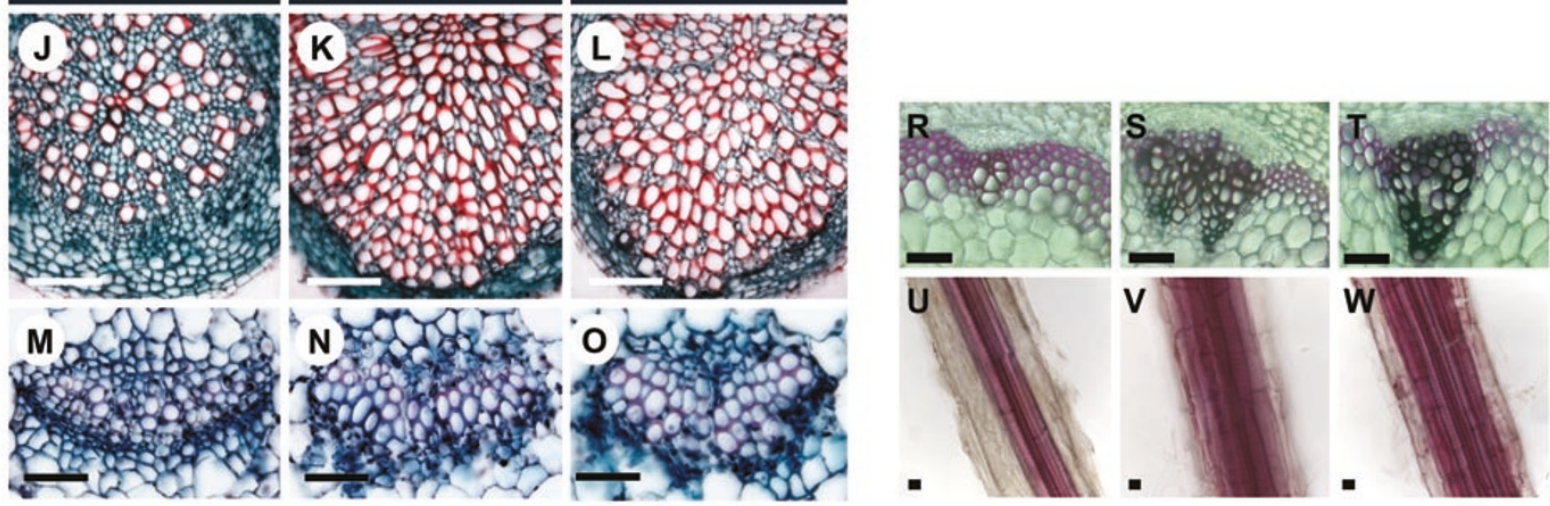

Figure 2 Comparison of vascular patterns of stems, roots and petioles between wild-type and bud2 plants. (A) to (C) Transverse sections of the first internodes of inflorescences of wild type (A), bud2-1 (B) and bud2-2 (C), observed under UV light (340-380 $\mathrm{nm}$ ). (D) to (F) Transverse sections of the first internodes of inflorescences of wild type (D), bud2-1 (E) and bud2-2 (F), observed under light microscope. (G) to (I) Transverse sections of main roots of wild type (G), bud2-1 (H) and bud2-2 (I), observed under UV light (340-380 nm). (J) to (L) Transverse sections of main roots of wild type (J), bud2-1 (K) and bud2-2 (L), observed under light microscope. (M) to (O) Vascular systems in petioles of wild type (M), bud2-1 (N) and bud2-2 (O), observed under light microscope. (P) and (Q) Lignin and cellulose contents (milligrams per gram of total cell wall residues) of wild-type, bud2-1 and bud2-2 plants.

(R) to (W) Wiesner's staining of the transverse sections of stems and longitudinal sections of lateral roots. (R) and (U) wild type; (S) and (V) bud2-1; (T) and (W) bud2-2. Bars in (A) to (O)=100 $\mu \mathrm{m}$ and in (R) to (W)=50 $\mu \mathrm{m}$.

with that of the wild type, but reduced to $\sim 56 \%$ when grown under light (data not shown). Moreover, the primary and lateral roots of bud2-1 were twisted and thicker than those of the wild-type plant (Figure 1L and 1M).

\section{Altered vascularization in bud2 plants}

To understand the alteration of the mutant plant at the cellular and tissue levels, we compared the anatomy of inflorescences, roots and petioles between bud 2 and wildtype plants (Figure 2). In the mature inflorescences of wild-type plants, vascular bundles are mainly composed of phloem and xylem, where the phloem pole at the outer side of the bundle is juxtaposed with the xylem pole at the inner side of the bundle. Vascular bundles are arranged in a circle and connected by interfascicular fibers, forming a hollow cylinder that surrounds a central parenchymatous pith (Figure 2A and 2D) [46]. Compared with wild type, the pattern of the vascular bundles and the hollow cylinder of bud2-1 inflorescences were largely affected (Figure $2 \mathrm{~B}$ and $2 \mathrm{E}$ ), due to a significant increase in the bundle size resulted from the increase in the number of tracheary vessels, although they were smaller than that of wild-type plants (Figure 2D and 2E).

Similar phenomenon was observed in the vascular 
system of roots (Figure $2 \mathrm{G}, 2 \mathrm{H}, 2 \mathrm{~J}$ and $2 \mathrm{~K}$ ). Unlike the wild-type root, in which there are normally eight layers of cortical cells outside the vascular bundles and the xylem elements were separately arranged (Figure $2 \mathrm{G}$ and $2 \mathrm{~J}$ ), the vascular bundles of bud2-1 occupied nearly all the space of root sections with apparently increased size of the xylem elements, which were closely arranged in the bundle (Figure $2 \mathrm{H}$ and $2 \mathrm{~K}$ ). Similar vascularization was also observed in the bud2-1 petiole vascular system (Figure $2 \mathrm{M}$ and $2 \mathrm{~N}$ ).

Since the main compositions of the vascular system are lignin and cellulose, we therefore measured their contents in bud 2-1 and wild-type plants. The lignin content in bud2-1 increased significantly, $30 \%$ higher than that in wild-type plants (Figure 2P). However, the cellulose contents between bud2-1 and wild type had no apparent difference (Figure 2Q). The increase of lignin content in bud2-1 plants was further confirmed by the Wiesner's staining of the sections of stems (Figure 2R and 2S) and lateral roots (Figure 2U and $2 \mathrm{~V}$ ). These results indicate that vascular development and lignin biosynthesis are greatly affected in bud2-1.

\section{Cloning and confirmation of BUD2}

Because genetic analysis indicated that the phenotypic segregation in the $F_{2}$ progeny fits the expectation for a single recessive nuclear mutation (wild-type: $\operatorname{mutant}=71$ : 25 ), it is very likely that the mutation in bud2-1 is due to a T-DNA insertion event. DNA gel-blot analysis of an $\mathrm{F}_{2}$ mapping population probed with the ${ }^{32} \mathrm{P}$-labelled $35 \mathrm{~S}$ promoter fragment demonstrated that the mutant phenotypes were cosegregated with a 4-kb DNA fragment (data not shown). Tail-PCR analysis revealed that the T-DNA flanking sequence was in the BAC clone F17K4, chromosome 5. However, further analysis with PCR amplification and DNA gel blot demonstrated that a 75-kb genomic DNA fragment was substituted by the inserted T-DNA, which was confirmed by an extended DNA fiber FISH of two BAC clones, T16G12 and F17K4, situated on this region (Figure 3A to 3D). Sequence analysis indicated that the deleted region may contain up to 20 putative open reading frames (ORFs). Among all these ORFs, the SAMDC gene (At5g18930), which is involved in the polyamine biosynthetic pathway, appears to be our candidate gene $B U D 2$, because the transgenic potato plants expressing an antisense cDNA of $S A M D C$ displayed a stunted phenotype with short internodes and small leaves [26]; the Arabidopsis acaulis5 (acl5) mutant defective in spermine biosynthesis $[11,23]$ and overexpression of $A D C$ were also bushy and dwarf [10]. Most importantly, another mutant collected from Salk T-DNA insertion stock (Salk 007279), in which T-DNA is inserted in the promoter region of At5g18930, also exhibited the same morphology as bud2-1 (Figure 1C,
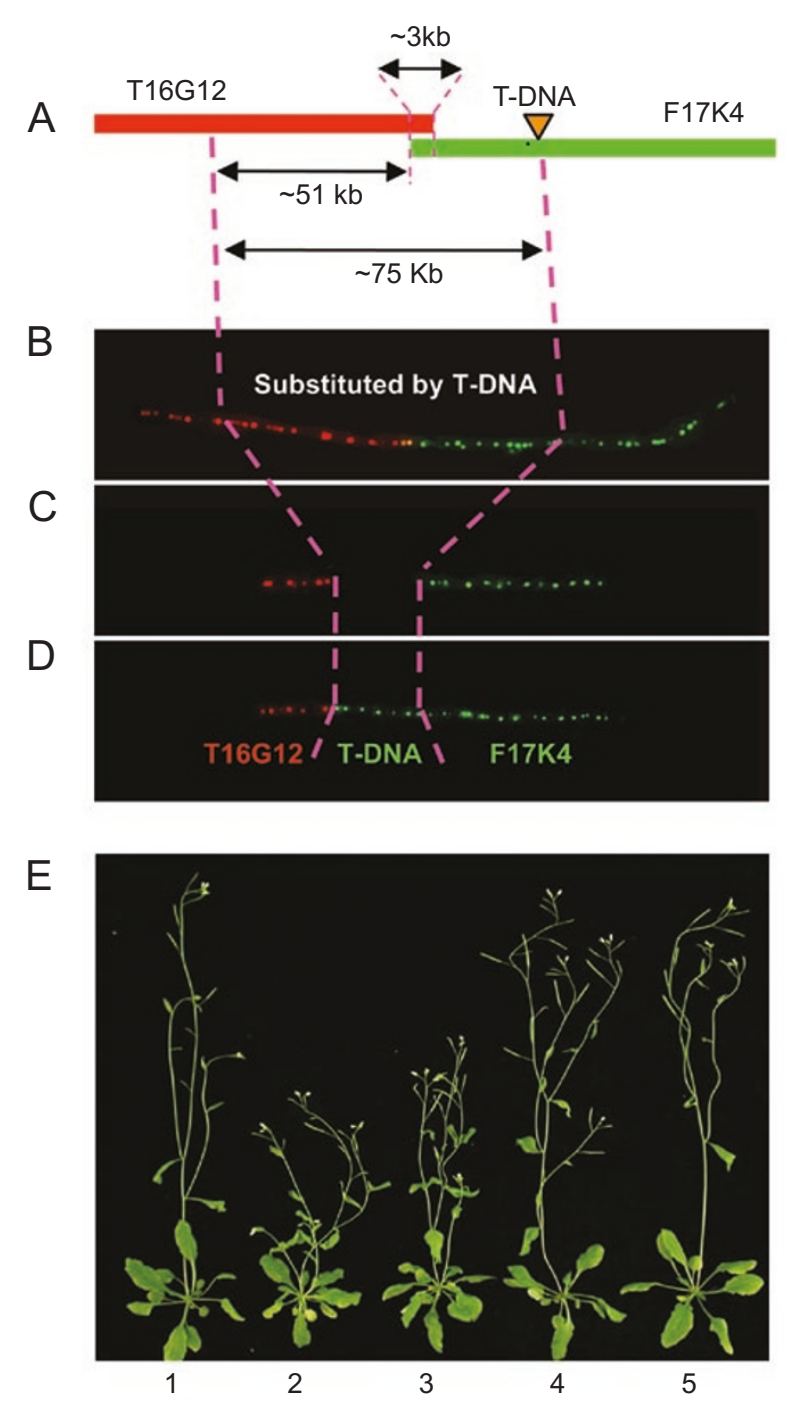

Figure 3 Chromosomal deletion in bud2-1 and complementation of mutants by BUD2. (A) Diagram of the $75-\mathrm{kb}$ deletion in the bud2-1 genome. Red bar represents BAC T16G12 and the green represents BAC F17K4. (B) Florescence hybridization of the BAC T16G12 (red) and F17K4 (green) to extended DNA fibers from wild-type Col-0 plants. (C) Florescence hybridization of the BAC T16G12 (red) and F17K4 (green) to extended DNA fibers of bud2-1, showing a gap in the bud2-1 genome and the truncation in both T16G12 and F17K4. T-DNA substitution for the gap was confirmed in (D). (D) Florescence hybridization of BAC T16G12 (red), T-DNA (green, middle) and BAC F17K4 (green, right) to the bud2-1 extended DNA fibers. (E) Complementation of bud2 mutants by the BUD2 gene. 1, Wild type; 2, bud2-1; 3, bud2-2; 4, complemented bud2-1; 5, complemented bud2-2.

$1 \mathrm{G}, 1 \mathrm{~K}$ and $1 \mathrm{~N})$. Further detailed histological examination revealed that the vascular morphology of Salk_007279 was highly similar to that of bud2-1 (Figure 2C, 2F, 2I, 2L, 


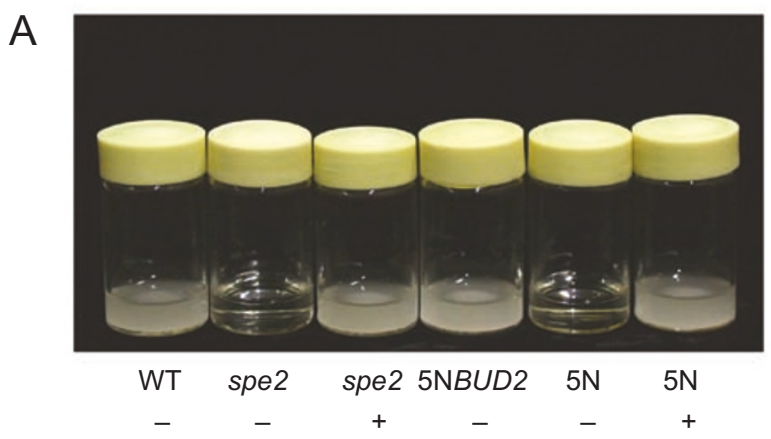

B

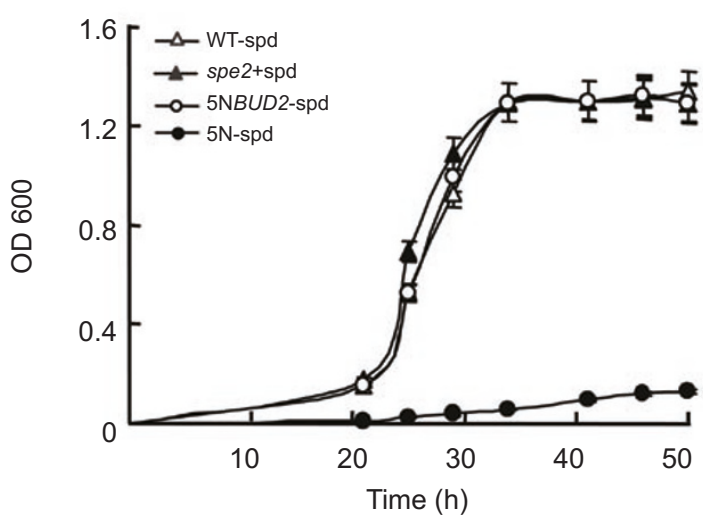

Figure 4 SAMDC activity of BUD2. (A) Functional complementation of yeast spe 2 mutant cells by BUD2. The yeast cells were cultured in the SD medium supplemented with $(+)$ or without $(-)$ spermidine. $5 \mathrm{~N} B U D 2$, spe 2 cells transformed with $B U D 2 ; 5 \mathrm{~N}$, spe 2 cells transformed with vector only. (B) Growth kinetics of SPE2 (triangle), spe2 (solid triangle) and spe2 transformed with BUD2 ( $5 \mathrm{~N} B U D 2$, circle), or vector ( $5 \mathrm{~N}$, solid circle). spd, spermidine.

\section{$2 \mathrm{O}, 2 \mathrm{~T}$ and $2 \mathrm{~W})$.}

To test whether BUD2 is the $S A M D C$ gene, a genomic DNA fragment containing the entire At5g18930 with its 5' and 3' regions was introduced into both bud2-1 and Salk_007279 genomes, and the transgenic plants exhibited the wild-type morphology (Figure 3E, Supplement 2). We also generated the transgenic plants expressing an antisense BUD2 cDNA under the control of $35 \mathrm{~S}$ cauliflower mosaic virus (CaMV) promoter and found that the transgenic plants displayed short internodes and reduced apical dominance as bud2-1 and Salk_007279 (data not shown). All these data demonstrate that it is the SAMDC (Accession number: DQ217414) that causes the phenotypic alterations in the bud2-1 and Salk_007279 plants. We therefore designated Salk_007279 as $\bar{b} u d 2-2$.

BUD2 encodes an isoform of S-adenosylmethionine decarboxylase
To confirm that BUD2 has the enzyme activity of SAMDC, we carried out a functional complementation experiment by expressing $B U D 2$ cDNA in the yeast mutant, spe2, in which the $S A M D C$ gene is disrupted and therefore the supplement of spermidine is required in the medium for its growth [35]. The spe 2 cells transformed with BUD2 grew normally as did the wild-type cells in the medium without supplement of spermidine, whereas spe2 cells alone or transformed with an empty vector could not grow without the supplement of spermidine (Figure 4A and 4B), indicating that BUD2 does have the enzymatic activity of SAMDC.

In the Arabidopsis genome, $S A M D C$ is a small gene family consisting of four highly homologous but distinguishable genes, SAMDC1 (At3g02470), SAMDC2 (At5g15950), SAMDC3 (At3g25570), and BUD2 or SAMDC4 (At5g18930) [29]. Phylogenetic analysis indicated that SAMDC1 and SAMDC2 had the highest (78\%) identity in amino acid sequences, whereas the SAMDC4 (BUD2) shared the lowest similarity to other members of SAMDC family (Figure 5A and 5B). Fortunately, another Salk T-DNA line, Salk_020185, was collected, in which the T-DNA was inserted in the 3' UTR of SAMDC1. We thus named it samdc1-1. The samdc1-1 plant exhibited a similar but even severer phenotype compared to the bud2-1 or bud2-2 plants (Figure $1 \mathrm{~F}$ to $1 \mathrm{H}$ ).

To explore the roles of SAMDCs, we examined their organ-specific expressions with RNA gel blot. As shown in Figure 5C, SAMDC1 was strongly expressed in all the examined organs with a relatively higher level in siliques, but $S A M D C 2$ was highly expressed in roots, leaves and flowers. $S A M D C 3$ was weakly expressed in all organs. BUD2 (SAMDC4), however, accumulated ubiquitously in all examined organs at a low level (Figure 5C), but was undetectable in bud 2-1 and bud2-2 (Figure 5D), consistent with the phenotypic observations. In samdc1-1, the SAMDC1 mRNA level was apparently decreased, but the $B U D 2$ transcripts were highly increased (Figure $5 \mathrm{D}$ ). No significant differences at the expression levels of $S A M D C 2$ and $S A M D C 3$ were observed among wild-type, bud 2 and samdc1 plants.

\section{Disrupted homeostasis of polyamines in bud2 plants}

Because SAMDCs are key enzymes in both spermidine and spermine biosynthesis, we therefore analyzed polyamine contents in wild type and bud2 plants. As shown in Table 1, compared to those in the wild type, the putrescine level in the bud2-1 plant increased by $\sim 25 \%$, whereas the contents of spermidine and spermine decreased by $\sim 9 \%$ and $16 \%$, respectively. Similar results were obtained from the bud2-2 mutant plant (Table 1). These results indicate that the disruption of $B U D 2$ leads to an abnormal homeostasis 
A BUD2 MAVS. 'GFEGFEKRLLRFEDDDKPITKNPMGTRLIDFESLDQVLNEVQC 48 SAMDC1 MALSAIGFEGYEKRLEVTFFEPSIFQDSKGLGLRALTKSQLDEILTPAAC 50 SAMDC2 MAMSAIGFEGYEKRLEVTFFEPGLFLDTQGKGLRALAKSQIDEILQPAEC 50 SAMDC3 YAVSATGEEGFEKRIEISEFETTDFLDPQGKSIRRLTKSQLDEILTPAEC 50

BUD2 IVVSAVANRSFDATVLSESSLEVYPTKIIIKTCGT'TQILSIRP. LIHIA 97 SAMDC1 TIVSSLSNDQLDSYVLSESSFEVYPYKVIIKTCGTTKLILSIPP. LLKLA 99 SAMDC2 TIVSSLSNDQLDSYVLSESSLE IFPYKIVIKTCGTTKLLLSIEP. LLRLA 99 SAMDC3 IIIVSSTNSFVDSYVLSESSLEVYPYKIIIKTCGTTKLILSI. PHILRLA 99

BUD2 RNEGITLRACRYSRGSFIFPKAQPFPYTSFKD JVIVVEESLPKSLCYRKA 147 SAMDC1 GELSISVKSVKYTRGSELCPGGQPFPHRSFSE EVSVLDGHFTQLGLNSVA 149 SAMDC2 GELSLDVKAVRYTRGSELCPGGQPFPHRNFSEEVSVLDGHFAKLGLSSVA 149 SAMDC3 DSTCTTVKSVRYTRES IFPGAOSYPHRSFSEIVALLDDYFGKLNAGSKA 149

BUD2 SVMTPSNNPSRAWHVETASADVES. . DEHVVVV WVCMTEWDRVNARSEF 194 SAMDC1 YLMG.NDDETKKNHVYAASA.QDSSNCNNNVYTLEMCMTGLDREKAAVEY 197 SAMDC2 YLMG.NDDETKKNHVYSASS. ANS. NNKNNVYTLEMCMTGLDKDKASVEY 196 SAMDC3 FVMGGSDNNPQRWHVYSASSTEESAVCDKPVYTLWMCMTGLDNIKASVEF 199

BUD2 KRKGDEKNNSDSAGKEIMIRLSGIDNINANAYICDEAFDPCGYSMINGVDGD 244 SAMDC1 K......DEADKTG. SMIDNSGIRKILPKSEICDEEFEPCGYSMNSIEGD 240 SAMDC2 K. . . NESSSAG.SMIDNSGIRKILPQSQICDEEFEPCGYSMNSIEGD 239

SAMDC3 K......TNSVSAS. EMIISSGIRNILPGSEICDENEEPCGYSMNSIEGD 242

BUD2 RYSTIHVTPEDGESYASFECGLSLYDNGHEDISEVLSRAIDVFRPSDVSI 294 SAMDC1 AISTIHVTPEDGFSYASFEAVG. YDFNTLDLSQLVTRVLSCFEPKQFSV 288 SAMDC2 AISTIHVTPEDGESYASFEAVG. YDFTTMDLSHLVSKVLTCFKPKQFSV 287 SAMDC3 AVSTTHVIPADGFSYASFTTG. MDLKALNFKELVDRVLVCFGPEEFSV 290

\begin{tabular}{|c|c|c|}
\hline BUD2 & TKRVER & \\
\hline SAMDC1 & GEESGTVMYQTE & 332 \\
\hline SAMDC2 & AVHSTVAQKSYDSGLSV. . . & 33 \\
\hline SAMDC3 & AVHANLGTEVLASDC . VA. . . . DVNGYFSQERELEELG. LGGSVLYORG & 333 \\
\hline BUD2 & TPRRK & 347 \\
\hline SAMDC1 & EK. LGKYCGSPRSTLKCEWSSNNSCSSEDEKDEGI & 366 \\
\hline SAMDC2 & EK. LGRYCGSPRSTLKCEWSSNSSCNSEDEK. E & 2 \\
\hline SAMDC3 & VKTV.ECC.SPKSTLG..F.....C & 349 \\
\hline
\end{tabular}

B

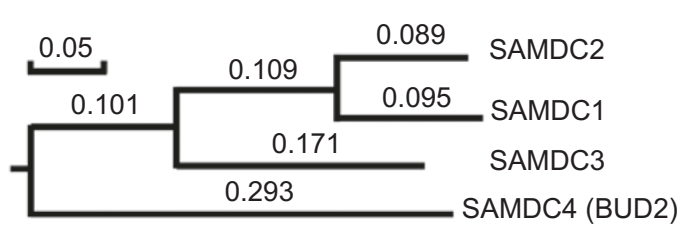

C

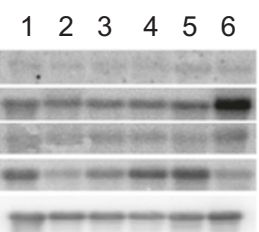

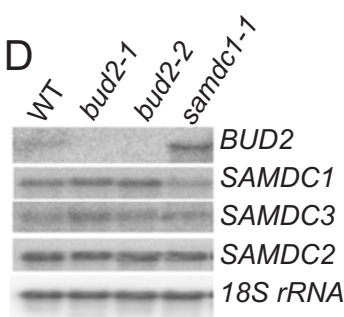

Figure 5 Arabidopsis SAMDCs and their expressions. (A) Homology analysis of SAMDCs in Arabidopsis. The identical aminoacid residues were shaded in the four SAMDCs. (B) Phylogenetic tree of SAMDCs in Arabidopsis. (C) Expressions of SAMDCs in various organs. 1 to 6 represents root, inflorescence stem, rosette leaf, cauline leaf, flower and silique, respectively. (D) Expressions of SAMDCs in wild-type, bud2-1, bud2-2 and samdc1-1 plants.

Table 1 Polyamine contents in wild type and bud2 plants ${ }^{\mathrm{a}}$

\begin{tabular}{llll}
\hline & Putrescine $\left(\mathrm{nmol} \mathrm{g}{ }^{-1} \mathrm{FW}\right)$ & Spermidine $\left(\mathrm{nmol} \mathrm{g}^{-1} \mathrm{FW}\right)$ & Spermine $\left(\mathrm{nmol} \mathrm{g} \mathrm{FW}^{-1}\right.$ \\
\hline Wild type & $27.8 \pm 0.43$ & $197.1 \pm 6.23$ & $35.3 \pm 4.49$ \\
bud2-1 & $34.8 \pm 3.69^{\mathrm{b}}(25.2 \%)^{\mathrm{c}}$ & $178.5 \pm 4.81^{\mathrm{b}}(-9.4 \%)^{\mathrm{c}}$ & $29.7 \pm 1.94^{\mathrm{b}}(-15.9 \%)^{\mathrm{c}}$ \\
bud2-2 & $31.0 \pm 2.63^{\mathrm{b}}(11.5 \%)^{\mathrm{c}}$ & $178.8 \pm 4.37^{\mathrm{b}}(-9.3 \%)^{\mathrm{c}}$ & $30.6 \pm 2.09^{\mathrm{b}}(-13.3 \%)^{\mathrm{c}}$ \\
\hline
\end{tabular}

${ }^{\mathrm{a}}$ Data represent means $\pm \mathrm{SD}$ from ten independent samples.

bIndicating the significant difference to wild type by Student's $t$ test.

${ }^{\mathrm{c}}$ Indicating the difference (\%) to wild type. 
Table 2 Genetic analysis of progeny derived from bud2 and samdc1

\begin{tabular}{|c|c|c|c|}
\hline Generation & Genotype & Phenotype & Individuals segregated \\
\hline $\mathrm{F} 1$ & BUD2bud2-1/SAMDC1samdc1-1 & Wild type & \\
\hline \multirow[t]{2}{*}{ F2 } & $B U D 2 \_/ S A M D C 1$ & Wild type & 178 \\
\hline & BUD2_/samdc1-1samdc1-1 & samdc1-1 & 58 \\
\hline $\begin{array}{l}\text { F3 (BUD2bud2-1/ } \\
\text { samdc1-1samdc1-1 }\end{array}$ & BUD2_/samdc1-1samdc1-1 & Normal seed & 129 \\
\hline
\end{tabular}

of polyamines.

\section{SAMDCs are essential for embryogenesis}

The fact that the complete deletion of SAMDC4 does not lead to the lethality of the bud2 mutant plant suggests that the $S A M D C$ genes might be, at least in part, functionally redundant. To verify their redundancy, we carried out a careful genetic analysis of the progeny derived from the crosses between samdc1-1 and bud2-1 or bud2-2. Among the $\mathrm{F}_{2}$ progeny, the segregated plants with abnormal phenotypes were either SAMDC1samdc1/bud2bud2 or samdc1samdc1/ BUD2bud2 genotype (Table 2), indicating that the double mutant samdclsamdc1/bud2bud2 is embryo lethal. We therefore examined the embryo developmental processes in the progeny derived from the self-pollinated $S A M D C$ 1 samdc1/bud2bud2 or samdc1samdc1/BUD2bud2 plants, and found that about one-quarter of seeds were apparently different from others as early as six DAP (days after pollination). These seeds looked bleached and transparent under microscope and became eventually decayed (Figure 6A to $6 \mathrm{C}$, Table 2). Microscopic examination revealed that the double mutant embryos began to show abnormalities at the globular stage and stopped further development afterwards (Figure 6D to 6M). This is consistent with the finding that the expression level of SAMDC1 is particularly high in siliques (Figure 5C). These results indicate that the SAMDC isogenes are essential for Arabidopsis embryogenesis.

\section{Discussion}

\section{Redundancy and essentiality of the SAMDC family}

In plants, the genes involved in the polyamine biosynthesis often belong to small families. So far, two members of $A D C, S P D S$ and SPMS genes [6, 19, 24, 47], and four members of $S A M D C$ genes have been identified in the Arabidopsis genome [29]. Previous studies indicated that $A D C$ and SPDS members are functionally redundant, because a mutation in either gene member does not cause significant phenotypic changes [20, 21, 24, 47]. Neverthe-

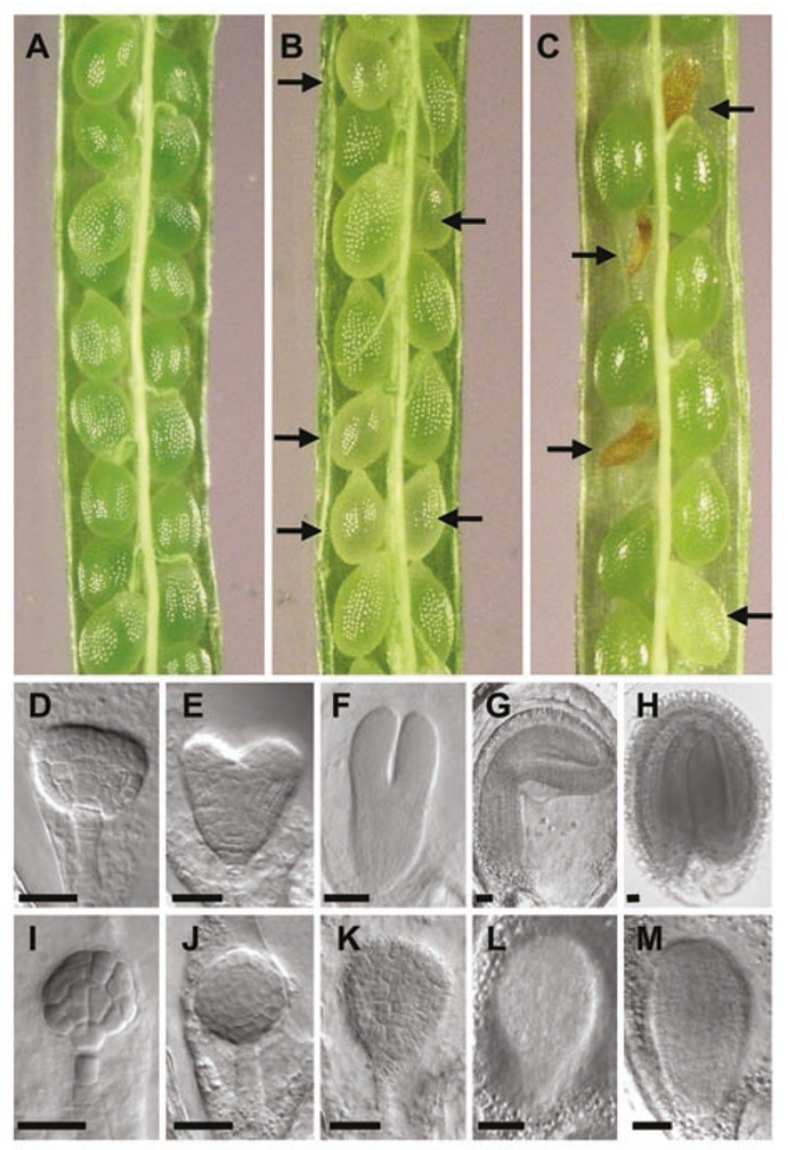

Figure 6 Embryo lethality of the bud2-1samdc1-1 double mutant. (A) to (C) Seed development of bud2-1samdc1-1 and wild-type plants at the stages of 8 days (8 DAP) of wild type (A) and bud2-1bud21/SAMDC1-1samdc1-1 (B), and 12 days (12 DAP) of bud2-1bud21/SAMDC1-1samdc1-1 (C). Arrows indicate aborted seeds. (D) to (H) Embryos of wild type at the triangle (D), heart (E), torpedo (F), bent-cotyledon (G) and mature (H) stages. (I) to (M) Embryos of bud2-1 bud2-1 samdc1-1 samdc1-1 at the stages as given in (D) to (H). Note that embryo development was arrested at the global stage and the seeds decayed eventually. Bars in (D) to $(\mathbf{M})=25 \mu \mathrm{m}$. 
less, the disruption of $A C L 5$, one of SPMS genes, results in a severe dwarfism and an increased organ vascularization $[11,22]$, indicating that two SPMS genes are not completely redundant during developmental process.

The characterization of bud 2 identified a mutation in one member of the $S A M D C$ family that encodes enzymes necessary for the biosynthesis of both spermidine and spermine and is considered to control the rate-limiting step in the polyamine biosynthetic pathway. Bushiness, dwarfism and altered vascular development in bud2-1 and bud2-2 demonstrate that disruption of one of the four $S A M D C$ genes, $S A M D C 4$, apparently affects growth and development, but does not cause lethality, indicating that functions of SAMDCs are partially redundant. This is supported by $S A M D C$ expressions in the samdc1-1 mutant, in which a decreased expression of $S A M D C 1$ is accompanied by the elevated expression of SAMDC4. On the other hand, the four SAMDCs are more likely to play different roles in an organ-specific or responsive manner. Among them, $S A M D C 1$ seems more important in affecting overall developmental processes, because knockdown mutant samdc1-1 not only displays a more severe phenotype but also elicits a compensatory expression of SAMDC4. Moreover, the different expression patterns of $S A M D C s$ in organs also imply that these SAMDCs might be involved in different developmental or responsive processes. However, the embryo lethality of bud2samdcl indicates that at least some SAMDCs are essential for plant survival. Therefore, further identification of loss of function mutants in SAMDC2 and $S A M D C 3$ is necessary to fully understand their roles in plant growth and development.

\section{Roles of plant polyamines}

Previous studies on animal cells have indicated that polyamines play very important roles in cell division and growth. For example, a circadian change of polyamine levels is observed during cell cycle [48] and the translation initiation factor eIF5A's biochemical activity on cellular proliferation is tightly linked to cellular polyamine homeostasis, especially to spermidine modification [49]. The observation on $O D C$ knockout mouse suggests that putrescine plays a key role in cell growth [50]. Moreover, the decreased level of spermine and spermidine is one of the important factors to induce cell apoptosis [18]. In plants, polyamines are not only important for both stress responses and developmental processes $[4,51,52]$ but also essential for plant survival, because the double mutants of $A D C s$, $S P D S s$ and SAMDCs are all embryo lethal [24, 47].

Different polyamines appear to have different functions in multicellular systems. In higher plants, putrescine might be more related to root initiation [53], even though controversy exists $[20,54]$. Our findings that bud2 plants contain more putrescine and have the enhanced root growth appear to support the argument that putrescine has a promotive effect on root growth. On the other hand, spermidine seems to be more important during developmental process, because it is more abundant in embryo and young organs [55], and most importantly, disruption of two SPDSs in Arabidopsis leads to embryo lethal [24]. Similarly, the embryo lethality of bud2samdcl may result from deficiency in spermidine. Spermine appears to be unessential for plant survival, but it may play a role in the vascular development; because an increased organ vascularization of the double mutant acl5spms 1 is observed, but its morphology is similar to that of acl5 [19, 22]. The enlarged vascular tissues and increased lignin content in bud2 might be attributable to the decreased spermine content. On the other hand, the bushy phenotype of bud2 and samdc1-1 suggests a possible involvement of auxin and/or cytokinin. Further analysis of bud2 and samdc1-1 responses to auxin and /or cytokinin might be helpful to understand the regulatory mechanism of polyamines in plant growth and development.

\section{Acknowledgements}

We thank Dr Senya Matsufuji (Jikei University, Japan) for providing the yeast spe2 strain, Dr Guixian Xia (Institute of Microbiology, Chinese Academy of Sciences, China) for yeast expression vector pREP5N and ABRC stock center for BAC clones (F17K4 and T16G12) and T-DNA insertion lines (Salk_007279 and Salk_020185). This work was supported by grants from National Natural Science Foundation of China (30330040) and the Ministry of Sciences and Technology of China (J02-A-001).

\section{References}

1 Smith TA. Polyamines. Annu Rev Plant Physiol 1985; 36:117143.

2 Tabor CW, Tabor H. Polyamines. Annu Rev Biochem 1984; 53:749-790.

3 Evans PT, Malmberg RL. Do polyamines have roles in plant development? Annu Rev Plant Physiol Plant Mol Biol 1989; 40:235-269.

4 Tiburcio AF, Campos JL, Figueras X, Bestford RT. Recent advances in the understanding of polyamine functions during plant development. Plant Growth Regul 1993; 12:331-340.

5 Cowley T, Walters DR. Polyamine metabolism in barley reacting hypersensitively to the powdery mildew fungus Blumeria graminis f. sp. hordei. Plant Cell Environ 2002; 25:461-468.

6 Pérez-Amador MA, Leon J, Green PJ, Carbonell J. Induction of the arginine decarboxylase $A D C 2$ gene provides evidence for the involvement of polyamines in the wound response in Arabidopsis. Plant Physiol 2002; 130:1454-1463.

7 Watson MB, Malmberg RL. Regulation of Arabidopsis thaliana (L.) Heynh Arginine decarboxylase by potassium deficiency stress. Plant Physiol 1996; 111:1077-1083. 
8 Tonon G, Kevers C, Faivre-Rampant O, Grazianil M, Gaspar T. Effect of $\mathrm{NaCl}$ and mannitol iso-osmotic stresses on proline and free polyamine levels in embryogenic Fraxinus angustifolia callus. J Plant Physiol 2004; 161:701-708.

9 Capell T, Bassie L, Christou P. Modulation of the polyamine biosynthetic pathway in transgenic rice confers tolerance to drought stress. Proc Natl Acad Sci USA 2004; 101:9909-9914.

10 Alcázar R, Garcia-Martinez JL, Cuevas JC, Tiburcio AF, Altabella T. Overexpression of ADC2 in Arabidopsis induces dwarfism and late-flowering through GA deficiency. Plant J 2005; 43:425-436.

11 Hanzawa Y, Takahashi T, Komeda Y. ACL5: an Arabidopsis gene required for internodal elongation after flowering. Plant J 1997; 12:863-874.

12 Ben-Hayyim G, Damon JP, Martin-Tanguy J, Tepfer D. Changing root system architecture through inhibition of putrescine and feruloyl putrescine accumulation. FEBS Lett 1994; 342:145-148.

13 Geuns JM, Smets R, Struyf T, et al. Apical dominance in Pssuipt-transformed tobacco. Phytochemistry 2001; 58:911-921.

14 Galston AW, Kaur-Sawhney R. Polyamines as endogenous growth regulators. In Davies PJ, ed Plant hormones. Kluwer Academic Publishers: Netherlands 1995:158-178.

15 Balasundaram D, Tabor CW, Tabor H. Spermidine or spermine is essential for the aerobic growth of Saccharomyces cerevisiae. Proc Natl Acad Sci USA 1991; 88:5872-5876.

16 Chattopadhyay MK, Tabor CW, Tabor H. Absolute requirement of spermidine for growth and cell cycle progression of fission yeast (Schizosaccharomyces pombe). Proc Natl Acad Sci USA 2002; 99:10330-10334.

17 Roberts SC, Scott J, Gasteier JE, et al. S-adenosylmethionine decarboxylase from Leishmania donovani. Molecular, genetic, and biochemical characterization of null mutants and overproducers. J Biol Chem 2002; 277:5902-5909.

18 Nishimura K, Nakatsu F, Kashiwagi K, et al. Essential role of S-adenosylmethionine decarboxylase in mouse embryonic development. Genes Cells 2002; 7:41-47.

19 Imai A, Akiyama T, Kato T, et al. Spermine is not essential for survival of Arabidopsis. FEBS Lett 2004; 556:148-152.

20 Watson MB, Emory KK, Piatak RM, Malmberg RL. Arginine decarboxylase (polyamine synthesis) mutants of Arabidopsis thaliana exhibit altered root growth. Plant J 1998; 13:231-239.

21 Soyka S, Heyer AG. Arabidopsis knockout mutation of $A D C 2$ gene reveals inducibility by osmotic stress. FEBS Lett 1999; 458:219-223.

22 Clay NK, Nelson T. Arabidopsis thickvein mutation affects vein thickness and organ vascularization, and resides in a provascular cell-specific spermine synthase involved in vein definition and in polar auxin transport. Plant Physiol 2005; 138:767-777.

23 Hanzawa Y, Takahashi T, Michael AJ, et al. ACAULIS5, an Arabidopsis gene required for stem elongation, encodes a spermine synthase. EMBO J 2000; 19:4248-4256.

24 Imai A, Matsuyama T, Hanzawa Y, et al. Spermidine synthase genes are essential for survival of Arabidopsis. Plant Physiol 2004; 135:1565-1573.

25 Mad Arif SA, Taylor MA, George LA, et al. Characterization of the S-adenosylmethionine decarboxylase $(S A M D C)$ gene of potato. Plant Mol Biol 1994; 26:327-338.

26 Kumar A, Taylor M, Mad Arif S, Davies H. Potato plants expressing antisense and sense S-adenosylmethionine decarboxylase
$(S A M D C)$ transgenes show altered levels of polyamines and ethylene: antisense plants display abnormal phenotypes. Plant J 1996; 9:147-158.

27 Dresselhaus T, Barcelo P, Hagel C, Lorz H, Humbeck K. Isolation and characterization of a Tritordeum cDNA encoding S-adenosylmethionine decarboxylase that is circadian-clock-regulated. Plant Mol Biol 1996; 30:1021-1033.

28 Tian AG, Zhao JY, Zhang JS, Gai JY, Chen SY. Genomic characterization of the S-adenosylmethionine decarboxylase genes from soybean. Theor Appl Genet 2004; 108:842-850.

29 Franceschetti M, Hanfrey C, Scaramagli S, et al. Characterization of monocot and dicot plant S-adenosyl-1-methionine decarboxylase gene families including identification in the mRNA of a highly conserved pair of upstream overlapping open reading frames. Biochem J 2001; 353:403-409.

30 Mou Z, He Y, Dai Y, Liu X, Li J. Deficiency in fatty acid synthase leads to premature cell death and dramatic alterations in plant morphology. Plant Cell 2000; 12:405-418.

31 Bechtold N, Pelletier G. In planta Agrobacterium-mediated transformation of adult Arabidopsis thaliana plants by vacuum infiltration. Methods Mol Biol 1998; 82:259-266.

32 Jackson SA, Wang ML, Goodman HM, Jiang J. Application of fiber-FISH in physical mapping of Arabidopsis thaliana. Genome 1998; 41:566-572.

$33 \mathrm{Hu}$ Y, Bao F, Li J. Promotive effect of brassinosteroids on cell division involves a distinct $C y c D 3$-induction pathway in Arabidopsis. Plant J 2000; 24:693-601.

34 Xia G, Ramachandran S, Hong Y, et al. Identification of plant cytoskeletal, cell cycle-related and polarity-related proteins using Schizosaccharomyces pombe. Plant J 1996; 10:761-769.

35 Chattopadhyay MK, Murakami Y, Matsufuji S. Antizyme regulates the degradation of ornithine decarboxylase in fission yeast Schizosaccharomyces pombe. Study in the spe 2 knockout strains. J Biol Chem 2001; 276:21235-21241.

36 Gupta R, Hamasaki-Katagiri N, White Tabor C, Tabor H. Effect of spermidine on the in vivo degradation of ornithine decarboxylase in Saccharomyces cerevisiae. Proc Natl Acad Sci USA 2001; 98:10620-10623.

37 Kirk Tk, Obst JR. Lignin determination. Methods Enzymol 1988; 161:87-101.

38 Li Y, Qian Q, Zhou Y, et al. BRITTLE CULM1, which encodes a COBRA-like protein, affects the mechanical properties of rice plants. Plant Cell 2003; 15:2020-2031.

39 Flores HE, Galston AW. Analysis of polyamines in higher plants by high performance liquid chromatography. Plant Physiol 1982; 69:701-707.

40 Li X, Qian Q, Fu Z, et al. Control of tillering in rice. Nature 2003; 422:618-621.

$41 \mathrm{Hu}$ WJ, Harding SA, Lung J, et al. Repression of lignin biosynthesis promotes cellulose accumulation and growth in transgenic trees. Nat Biotechnol 1999; 17:808-812.

42 Strivastava LM. Histochemical studies on lignin. Tappi 1966; 49:173-183.

43 Liu F, Ni W, Griffith ME, et al. The ASK1 and ASK2 genes are essential for Arabidopsis early development. Plant Cell 2004; 16:5-20.

44 Mou Z, Wang X, Fu Z, et al. Silencing of phosphoethanolamine $\mathrm{N}$-methyltransferase results in temperature-sensitive male sterility and salt hypersensitivity in Arabidopsis. Plant Cell 2002; 
14:2031-2043.

45 Dai Y, Wang H, Li B, et al. Increased expression of MAP KINASE KINASE7 causes deficiency in polar auxin transport and leads to plant architectural abnormality in Arabidopsis. Plant Cell 2006; 18:308-320.

46 Ye ZH, Freshour G, Hahn MG, Burk DH, Zhong R. Vascular development in Arabidopsis. Int Rev Cytol 2002; 220:225-256.

47 Urano K, Hobo T, Shinozaki K. Arabidopsis ADC genes involved in polyamine biosynthesis are essential for seed development. FEBS Lett 2005; 579:1557-1564.

48 Wallace HM, Fraser AV, Hughes A. A perspective of polyamine metabolism. Biochem J 2003; 376:1-14.

49 Jenkins ZA, Haag PG, Johansson HE. Human eIF5A2 on chromosome $3 \mathrm{q} 25-\mathrm{q} 27$ is a phylogenetically conserved vertebrate variant of eukaryotic translation initiation factor $5 \mathrm{~A}$ with tissue-specific expression. Genomics 2001; 71:101-109.
50 Li F, Hua SB, Wang CC, Gottesdiener KM. Procyclic Trypanosoma brucei cell lines deficient in ornithine decarboxylase activity. Mol Biochem Parasitol 1996; 78:227-236.

51 Torrigiani P, Altamura MM, Pasqua G, et al. Free and conjugated polyamines during de novo floral and vegetative bud formation in thin cell layers of tobacco. Physiol Plant 1987; 70:453-460.

52 Walters DR. Polyamines and plant disease. Phytochemistry 2003; 64:97-107.

53 Walden R, Cordeiro A, Tiburcio AF. Polyamines: small molecules triggering pathways in plant growth and development. Plant Physiol 1997; 113:1009-1013.

54 Tonon G, Kevers C, Gaspar T. Changes in polyamines, auxins and peroxidase activity during in vitro rooting of Fraxinus angustifolia shoots: an auxin-independent rooting model. Tree Physiol 2001; 21:655-663.

55 Galston AW, Sawhney RK. Polyamines in plant physiology. Plant Physiol 1990; 94:406-410.

Edited by Hong Wei Xue 